\title{
Essential Role of Filopodia in Chemotropic Turning of Nerve Growth Cone Induced by a Glutamate Gradient
}

\author{
James Q. Zheng, Ji-jun Wan, and Mu-ming Poo \\ Department of Biological Sciences, Columbia University, New York, New York 10027
}

Pathfinding of growing neurites depends on turning of the growth cone in response to extracellular cues. Motile filopodia of the growth cone are known to be critical for mediating contact-dependent guidance of the growth cone. However, whether filopodia also play an essential role in growth cone turning response induced by a diffusible chemotropic substance is unclear. Growth cones of cultured Xenopus spinal neurons exhibited chemotropic turning responses in a gradient of glutamate within a limited range of concentrations. This turning response depends on the activation of the NMDA subtype of glutamate receptors and requires the presence of extracellular $\mathrm{Ca}^{2+}$. Time-lapse differential interference contrast microscopy with quantitative analysis of filopodia dynamics showed a close correlation between an increased number of filopodia on the side of the growth cone facing the glutamate source and the turning. Such filopodia asymmetry was observed within minutes after the onset of the glutamate gradient, before any detectable turning of the growth cone. In $\mathrm{Ca}^{2+}$-free medium, no filopodia asymmetry was induced by the glutamate gradient, and no growth cone turning was observed. Furthermore, elimination of filopodia with a low concentration of cytochalasin B completely abolished the turning response without substantially affecting neurite extension. Thus, filopodia may be required for chemotropic guidance of the growth cone, and an asymmetry in filopodia distribution may be an early cellular event responsible for determining the direction the growth cone advances.

Key words: growth cone guidance; filopodia asymmetry; $\mathrm{Ca}^{2+}$; chemotropism; glutamate receptors; actin
Formation of specific nerve connections during development requires guidance of growing nerve processes to their correct target cells. This guidance depends on the response of growth cones to extracellular cues, which include specific molecules bound to extracellular matrix or cell surfaces as well as diffusible chemotropic substances (Lockerbie, 1987; Bray and Hollenbeck, 1988; TessierLavigne, 1992; Goodman and Shatz, 1993). Although the cellular processes by which the growth cone detects and responds to guidance cues are largely unknown, motile filopodia at the leading edge of the growth cone appear to play an important role (Gundersen and Barrett, 1980; Raper et al., 1983; Bentley and Toroian-Raymond, 1986; McCaig, 1986; Bandtlow et al., 1990; O'Connor et al., 1990; IIeidemann and Buxbaum, 1991; Letourneau et al., 1991). Filopodia may act by sensing guidance cues (Davenport et al., 1993; Gomez and I etourneau, 1994) or by exerting tension on the growth cone to initiate the turning (Wessells and Nuttall, 1978; Heidemann et al., 1990). Neurite extension in cell cultures persists after filopodia are disrupted by cytochalasin B (CB) (Marsh and Letourneau, 1984). However, after cytochalasin-induced disappearance of filopodia, a large percentage of pioneering growth cones in grasshopper embryos became disoriented in their pathfinding because of the lack of filopodial contact with specific guidepost cells (Bentley and ToroianRaymond, 1986). In cytochalasin-treated Xenopus embryos, there was also an increased number of errors in the pathfinding of retinal axons in the tectum (Chien et al., 1993). These studies have established the critical importance of filopodia in contact-mediated pathfinding. In the present study, we have examined whether filopodia are also required for guidance involving diffusible chemotropic sub-

Received Sept. 22, 1995; revised Nov. 1, 1995; accepted Nov. 5, 1995.

Correspondence should be addressed to Mu-ming Poo, Department of Biology, University of California at San Dicgo, La Jolla, CA 92093.

Copyright $\mathcal{C} 1996$ Socicty for Neuroscience $0270-6474 / 96 / 161140-10 \$ 05.00 / 0$ stances. We found that an early appearance of asymmetric filopodia distribution at the growth cone correlates with the turning response of the growth cones of Xenopus spinal neurons in a gradient of glutamate. Depletion of extracellular $\mathrm{Ca}^{2+}$, a condition that abolishes the turning response, also abolished the filopodia asymmetry. When filopodia were eliminated by treatment with $\mathrm{CB}$, glutamateinduced turning was abolished totally. These results provide direct evidence for an essential role of filopodia in growth cone guidance by gradients of diffusible substances.

\section{MATERIALS AND METHODS}

Cell culture. Cultures of Xenopus spinal neurons were prepared according to procedures reported previously (Spitzer and Lamborghini, 1976; Tabti and Poo, 1991). Briefly, the neural tube tissue from 1-d-old embryos (stage 20-22) (Nieuwkoop and Faber, 1976) was dissociated in $\mathrm{Ca}^{2+}$ / $\mathrm{Mg}^{2+}$-free Ringer's solution supplemented with EDTA $(115 \mathrm{~mm} \mathrm{NaCl}$, $2.5 \mathrm{~mm} \mathrm{KCl}, 10 \mathrm{~mm}$ HEPES, and $0.5 \mathrm{~mm}$ EDTA, pH 7.4), plated on clean glass coverslips, and incubated at room temperature $\left(20-22^{\circ} \mathrm{C}\right)$ for $6-12$ $\mathrm{hr}$ before the experiments. The culture medium consisted of $50 \%(\mathrm{v} / \mathrm{v})$ Leibovitz medium (Gibco, Gaithersburg, MD), 1\% (v/v) fetal bovine serum (HyCylone, Logan, UT), and 49\% (v/v) Ringer's solution (115 mM $\mathrm{NaCl}, 2 \mathrm{mM} \mathrm{CaCl}_{2}, 2.5 \mathrm{~mm} \mathrm{KCl}$, and $10 \mathrm{~mm}$ HEPES, $\mathrm{pH}$ 7.4). This culture medium contained $\sim 1 \mathrm{mM}$ glycine and $1 \mathrm{mM} \mathrm{Mg}^{2+}$.

Production of microscopic gradient of glutamate. A microscopic concentration gradient of glutamate was produced by repetitive pulsatile ejection of glutamate solution through a glass micropipette according to previously reported methods (Lohof et al., 1992; Zheng et al., 1994). Briefly, micropipettes with a tip opening of $1 \mu \mathrm{m}$ were filled with the glutamate solution and connected to an electrically gated pressureapplication system (Picospritzer, General Valve, Fairfield, NJ). Glutamate was ejected by applying positive pressure of 3 psi to the pipette at a frequency of $2 \mathrm{~Hz}$ and a pulse duration of $20 \mathrm{msec}$ using a pulse generator (Grass SD9, Grass Instruments, Quincy, MA).

Standard chemotropic test. Experiments on growth cone turning were performed on the stage of an inverted phase-contrast microscope. The direction of neurite extension at the onset of the experiment was defined by the last $20 \mu \mathrm{m}$ segment of the neurite. The tip of the glutamate pipette 

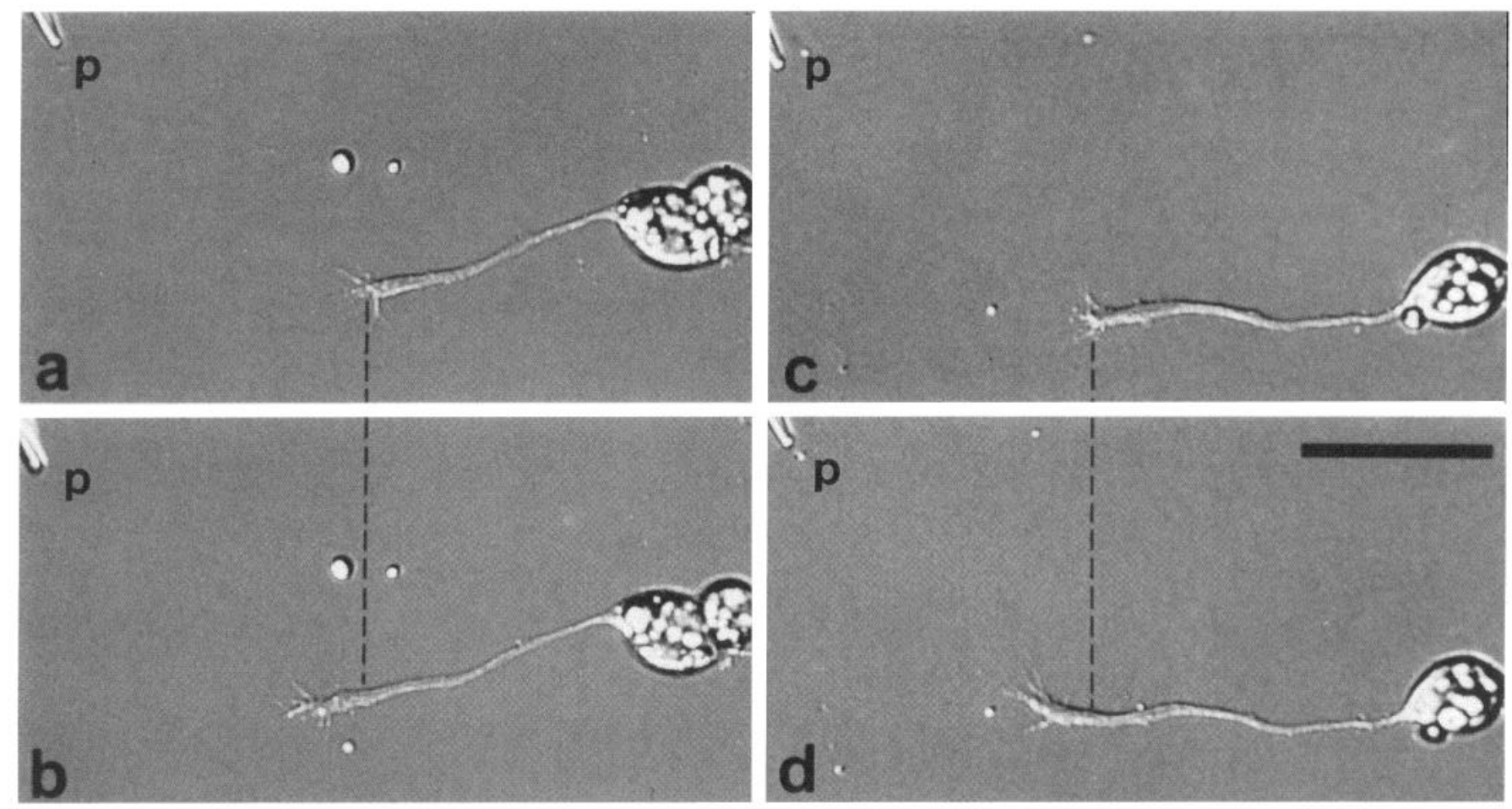

Figure 1. Turning response of Xenopus spinal neurons in the presence of a glutamate gradient. Representative DIC images of neurons at the onset and $1 \mathrm{hr}$ after repetitive applications of picoliters of fresh culture medium $(a, b)$ or medium containing $0.5 \mathrm{~mm}$ glutamate $(c, d)$ through a micropipette $(p)$. Dashed line indicates corresponding positions along the neurite. Scale bar, $50 \mu \mathrm{m}$.

was positioned $100 \mu \mathrm{m}$ away from the center of the phase-dark "palm" of the growth cone with an angle of $45^{\circ}$ from the initial direction of the neurite extension. Microscopic images of neurons at various times after the onset of glutamate application were recorded with a video camera and stored. For quantitative analysis of neurite growth and turning, the trajectory of each neurite before and $1 \mathrm{hr}$ after the onset of the gradient was traced from the video images, and the final position of the growth cone was determined in polar coordinates, with the origin set at the position of the growth cone at the onset of the gradient. The turning angle and extension of the neurite for each case were measured using a digitizing pad (Hipad, Houston Instruments, Houston, TX). The turning angle was defined by the angle between the original direction of neurite extension and a line connecting the positions of the growth cone at the onset and the end of $1 \mathrm{hr}$ exposure to the gradient. The length of neurite extension was obtained by measuring the length of the entire trajectory of the path of neurite growth over the $1 \mathrm{hr}$ period. Only the growth cones that extended $>5 \mu \mathrm{m}$ during the $1 \mathrm{hr}$ period were scored for the turning assay.

Differential interference contrast imaging of filopodia distribution. Cells were examined with a Zeiss inverted microscope (Axiovert, Zeiss, Thornwood, NY) equipped with differential interference contrast (DIC) optics and an imaging system based on a cooled charge-coupled device (CCD) camera (STAR I, Photometrics, Tucson, AZ). To visualize the filopodia, a $40 \times$ oil-immersion objective with a numerical aperture of 0.9 was used. Time-lapse sequences of DIC images of the growth cone before and after the onset of a glutamate gradient were collected by the CCD camera with the aid of a time-lapse imaging program. As a standard procedure, time-lapse recordings were performed at a rate of $1 \mathrm{frame} / 10 \mathrm{sec}$, and the collected images were stored in a digital format. The growth cone was observed for $5 \mathrm{~min}$ before (as control) and for $15 \mathrm{~min}$ after the onset of the glutamate gradient. For analysis of filopodia, the images of the time-lapse sequences were displayed, magnified, and contrast-enhanced further. A line was drawn along the midline of the growth cone palm and the neurite shaft, and the number and average length of filopodia on the two sides of the line were determined. Analysis of filopodia number was done for every frame of the sequence, and measurement of filopodia length was done for every sixth frame. A nonparametric test (KruskalWallis test) was performed between data collected during the $5 \mathrm{~min}$ control period and those collected during each of the three 5 min periods after the onset of the glutamate gradient.
Drug administration. ( \pm )2-Amino-5-phosphonopentanoic acid (AP-5), a specific NMDA-receptor antagonist, and 6-cyano-7-nitroquinoxaline2,3-dione (CNQX), a specific antagonist to non-NMDA glutamate receptors, were obtained from Research Biochemicals (Natick, MA). AP-5 and CNQX were freshly diluted before each experiment and were used at a final concentration of $25 \mu \mathrm{M}$. CB was obtained from Sigma (St. Louis, MO). CB first was dissolved in dimethylsulfoxide at $5 \mathrm{mg} / \mathrm{ml}$ as stock solution and was diluted to a low concentration $(0.17 \mu \mathrm{g} / \mathrm{ml})$ in culture medium immediately before use. The cells were incubated for $20 \mathrm{~min}$ in culture medium containing $\mathrm{CB}$ to achieve complete disruption of filopodia before the start of glutamate application.

Fluorescent staining of F-actin. Distribution of F-actin in the growth cone was visualized by labeling with rhodamine-conjugated phalloidin. Briefly, cells were fixed in $4 \% p$-formaldehyde in cacodylic buffer $(0.1 \mathrm{M}$ cacodylic acid and $0.1 \mathrm{~m}$ sucrose, $\mathrm{pH} 7.4$ ) for $30 \mathrm{~min}$, permeabilized by $0.1 \%$ Triton $\mathrm{X}-100$ in Ringer's solution for $10 \mathrm{~min}$, and stained with the rhodamine-phalloidin solution ( $1 \%$ of the $300 \mathrm{U}$ stock in methanol; Molecular Probes, Eugene, OR). Fluorescent images of the growth cone were collected by the CCD camera and stored in a digital format.

\section{RESULTS}

\section{Turning of nerve growth cones in a glutamate gradient}

Within 6-10 hr after plating in culture, dissociated embryonic Xenopus spinal neurons exhibited active neurite extension. In a standard test of chemotropic response, picoliter pulses of solution containing chemotropic substances were applied repetitively through a micropipette at a frequency of $2 \mathrm{~Hz}$. The pipette tip was positioned $100 \mu \mathrm{m}$ from the center of the growth cone and $45^{\circ}$ from the direction of neurite extension. Previous analyses have shown that relatively stable concentration gradients of $\sim 10 \%$ can be established across a $10 \mu \mathrm{m}$ distance, which is approximately the width of a growth cone (Lohof et al., 1992; Zheng et al., 1994). Pulsatile application of culture medium alone did not produce any effects on neurite orientation (Fig. $1 a, b$ ). However, application of solution containing appropriate concentrations of glutamate caused a turning response of the growth cone toward the source of 
glutanate, as defined by a preferential advancenent of the central palm of the growth cone (Fig. $1 c, d$ ). Most growth cones showed clear turning responses within $30 \mathrm{~min}$ after the onset of the glutamate gradient. For better assessment of the turning response and the growth rate, growth cones were examined $1 \mathrm{hr}$ after the onset of the glutamate gradient in all experiments.

The growth cone behavior in the presence of chemical gradients was quantified by measuring the turning angle and neurite extension. The turning angle was defined as the angle between the original direction of neurite extension and a line connecting the positions of the growth cone at the onset and the end of $1 \mathrm{hr}$ exposure to the gradient. We consider growth cones with turning angles of $>5^{\circ}$ as showing positive (toward the source) or negative (away from the source) turning. The results of all growth cones exposed to the control solution or to the glutamate-containing solution are depicted in the scatter plots of Figure 2, $a$ and $b$. For a population of neurons, no obvious preferential turning was observed after pulsatile applications of culture medium alone ( $n$ $=37$; Fig. 2a), whereas a majority of growth cones showed positive turning responses when glutamate $(0.5 \mathrm{~mm}$ in the pipette) was applied ( $n=38$; Fig. $2 b$ ). To illustrate the turning behavior of the growth cone better, the trajectory of neurite extension of 20 randomly selected neurons during the $1 \mathrm{hr}$ period is shown in a composite drawing (Fig. 2c,d). Growth cones exposed to culture medium alone showed extension with a similar frequency of positive and negative turning (Fig. 2c). In the presence of a glutamate gradient, a significantly larger number of the growth cones grew toward the source of glutamate than turned away (Fig. $2 d)$. The turning response of the growth cone depended on the concentration of glutamate in the pipette solution. A range of glutamate concentrations from 0 to $150 \mathrm{~mm}$ was tested. Significant chemotropic turning was observed only for concentrations at 0.05 and $0.5 \mathrm{~mm}$ (see Fig. $2 e$, Table 1). Although at some concentrations (e.g., $50 \mathrm{~mm}$ ), more growth cones appeared to exhibit positive turning, the average turning angles were close to zero, and statistical analysis on the turning angle showed no significant difference from that of control at these concentrations. Apparently, small degrees of positive turning and large degrees of negative turning accounted for the discrepancy between the results obtained by the two methods.

The turning response of the growth cone, when induced in culture medium, requires the activation of both NMDA and non-NMDA glutamate receptors, because either AP-5, a specific NMDA-receptor antagonist, or CNQX, a specific non-NMDAreceptor antagonist, can block the turning induced by the glutamate gradient at the optimal concentration for inducing turning (see Table 1). Extracellular $\mathrm{Mg}^{2+}$ is known to block NMDAreceptor activity in a voltage-dependent manner (Nowak et al., 1984; Jahr and Stevens, 1987). In the absence of extracellular $\mathrm{Mg}^{2+}\left(\mathrm{Mg}^{2+}\right.$-free solution: $115 \mathrm{~mm} \mathrm{NaCl}, 2.6 \mathrm{~mm} \mathrm{KCl}, 2 \mathrm{~mm}$

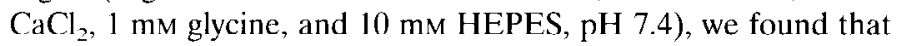
the glutamate-induced turning was blocked by AP-5 but not by CNQX (Table 1). This result indicates that NMDA receptors are primarily responsible for the turning. In the presence of $\mathrm{Mg}^{2+}$, both NMDA and non-NMDA receptors are required for glutamate-induced turning. Activation of non-NMDA receptors can cause membrane depolarization, which apparently is required for the removal of $\mathrm{Mg}^{2+}$ block of NMDA receptors.

Activation of NMDA receptors permits the influx of extracellular $\mathrm{Ca}^{2+}$. To test whether glutamate-induced turning requires a $\mathrm{Ca}^{2+}$ influx, we performed the turning experiment in a $\mathrm{Ca}^{2+}$-free medium (115 mM NaCl, $2.6 \mathrm{~mm} \mathrm{KCl,} 2 \mathrm{~mm} \mathrm{MgCl}, 10 \mathrm{~mm}$ HEPES,
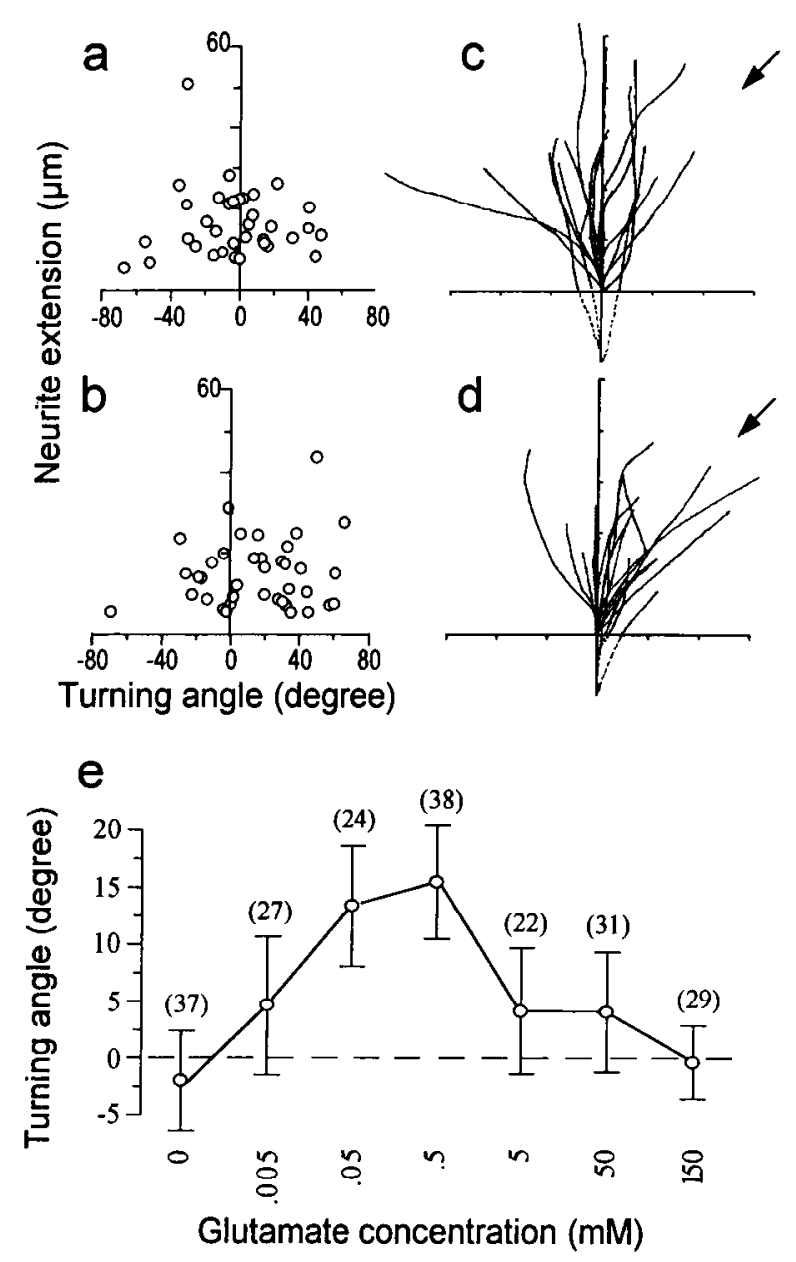

Figure 2. Summary of the chemotropic turning response induced by a gradient of glutamate. $a, b$, Scatter plots of all data corresponding to chemotropic experiments in which control culture medium $(a)$ and medium containing $0.5 \mathrm{mM}$ glutamate $(b)$ were applied, respectively. Each point represents the turning angle and the neurite extension (as defined in Materials and Methods) observed for a $1 \mathrm{hr}$ experiment on a growth cone. $c, d$, Composite drawings of the path of neurite extension during a $1 \mathrm{hr}$ period for a population of neurons in the absence $(c)$ and presence $(d)$ of glutamate gradient. For clarity, only 20 randomly sampled neurons from $a$ and $b$ are illustrated in each drawing. The origin represents the position of the center of the growth cone palm at the beginning of the $1 \mathrm{hr}$ period. The original direction of neurite extension, as defined by the last $20 \mu \mathrm{m}$ segment of the neurite shaft at the beginning of the experiment, was aligned with the vertical scale line. The line depicts the trajectory of the neurite at the end of the 1 hr experiment. The arrow indicates the direction of glutamate gradient. Tick marks along the $x$-and $y$-axis represent $10 \mu \mathrm{m}$. Note that some neurites had retracted a short distance from the origin before subsequent extension (dashed lines). $e$, Turning responses at different glutamate concentrations. The concentration in the pipette was varied from 0 to $150 \mathrm{mM}$, and the average turning angle ( \pm SEM) was determined by a standard protocol (see Materials and Methods). The number associated with each bar refers to the number of growth cones tested. Significant turning was observed for glutamate concentrations at 0.05 and $0.5 \mathrm{~mm}(p<0.05$, Kruskal-Wallis test compared with data at $0 \mathrm{~mm}$ ).

and 2 mм EGTA, pH 7.4). Similar to that found in acetylcholine (ACh)-induced turning of these growth cones (Zheng et al., 1994), no turning response was induced by the glutamate gradient (Table 1). Consistent with previous reports (Bixby and Spitzer, 1984a; Zheng et al., 1994), the rate of neurite extension in this $\mathrm{Ca}^{2+}$-free medium was increased markedly. 
Table 1. Response of Xenopus nerve growth cones in glutamate gradients

\begin{tabular}{|c|c|c|c|c|c|c|c|}
\hline \multirow{2}{*}{$\begin{array}{l}\text { Glutamate in } \\
\text { pipette (mM) }\end{array}$} & \multirow{2}{*}{$\begin{array}{l}\text { Changes in culture } \\
\text { medium }\end{array}$} & \multirow{2}{*}{$\begin{array}{l}\text { Turning angle } \\
\text { (degrees) }^{a}\end{array}$} & \multirow{2}{*}{$\begin{array}{l}\text { Neurite } \\
\text { extension }(\mu \mathrm{m})^{a}\end{array}$} & \multicolumn{3}{|c|}{ Turning responses $(\%)^{C}$} & \multirow[b]{2}{*}{$n$} \\
\hline & & & & + & 0 & - & \\
\hline 0 & None & $-2.7 \pm 4.4$ & $16.5 \pm 1.4$ & 38 & 22 & 40 & 37 \\
\hline 0.005 & None & $4.7 \pm 6.0$ & $18.9 \pm 1.7$ & 52 & 18 & 30 & 27 \\
\hline 0.05 & None & $13.4 \pm 5.2^{b}$ & $13.3 \pm 1.2$ & 63 & 8 & 29 & 24 \\
\hline 0.5 & None & $15.5 \pm 4.8^{b}$ & $14.9 \pm 1.4$ & 61 & 18 & 21 & 38 \\
\hline 5 & None & $4.2 \pm 5.4$ & $15.9 \pm 2.1$ & 45 & 14 & 41 & 22 \\
\hline 50 & None & $4.1 \pm 5.1$ & $16.7 \pm 1.7$ & 61 & 7 & 32 & 31 \\
\hline 150 & None & $-0.3 \pm 3.1$ & $14.9 \pm 1.2$ & 31 & 38 & 31 & 29 \\
\hline 0.5 & AP-5 $(25 \mu \mathrm{M})$ & $-1.5 \pm 4.5$ & $12.6 \pm 1.3$ & 29 & 25 & 46 & 24 \\
\hline 0.5 & CNQX $(25 \mu \mathrm{M})$ & $-3.4 \pm 3.9$ & $12.7 \pm 1.4$ & 31 & 38 & 31 & 26 \\
\hline 0.5 & $\mathrm{AP}-5+\mathrm{Mg}^{2+}-$ free $^{d}$ & $0.9 \pm 4.6$ & $16.3 \pm 1.8$ & 38 & 24 & 38 & 20 \\
\hline 0.5 & $\mathrm{CNQX}+\mathrm{Mg}^{2+}-$ free $^{d}$ & $13.5 \pm 4.9^{b}$ & $10.8 \pm 1.2^{b}$ & 60 & 10 & 30 & 21 \\
\hline 0.5 & $\mathrm{CB}(0.17 \mu \mathrm{g} / \mathrm{ml})$ & $0.6 \pm 3.1$ & $10.9 \pm 0.9^{b}$ & 36 & 32 & 32 & 25 \\
\hline 0.5 & $\mathrm{Ca}^{2+}-$ free & $-2.9 \pm 5.4$ & $40.4 \pm 5.0^{b}$ & 42 & 11 & 47 & 19 \\
\hline
\end{tabular}

${ }^{a}$ The glutamate gradient was established by pulsatile ejection of glutamate solution into the bath through a micropipette $100 \mu \mathrm{m}$ away from the growth cone and with an angle of $45^{\circ}$ with respect to the direction of neurite extension. The turning angles with respect to the original direction of neurite extension were determined by a straight line connecting the position of the growth cone at $1 \mathrm{hr}$ after the onset of glutamate application to that at the onset. The length of neurite extension was measured for the entire trajectory of the path of the extension over the $1 \mathrm{hr}$ period. Only growth cones advanced $>5 \mu \mathrm{m}$ were scored for turning assay. Values represent mean \pm SEM.

${ }^{b}$ Significantly different from the control value (zero glutamate, first row, $p<0.05$; nonparametric Kruskal-Wallis test).

'The turning responses of growth cones were scored as follows: plus sign refers to the percentage of cells showing positive turning towards the glutamate source (turning angle $>5^{\circ}$ ), minus sign refers to cells turning away from the glutamate source (turning angle $<-5^{\circ}$ ), and "zero" refers to cells showing no turning (turning angle $\leq 5^{\circ}$ ).

${ }^{d} \mathrm{Mg}^{2+}$-free medium: $115 \mathrm{~mm} \mathrm{NaCl}, 2.6 \mathrm{~mm} \mathrm{KCl}, 2 \mathrm{~mm} \mathrm{CaCl}_{2}, 1$ mм glycine, $10 \mathrm{~mm}$ HEPES, pH 7.4.

eCalcium-free medium: 115 mм NaCl, 2.6 mм KCl, 2 mм MgCl 2,2 mм EGTA, 10 mм HEPES, pH 7.4.
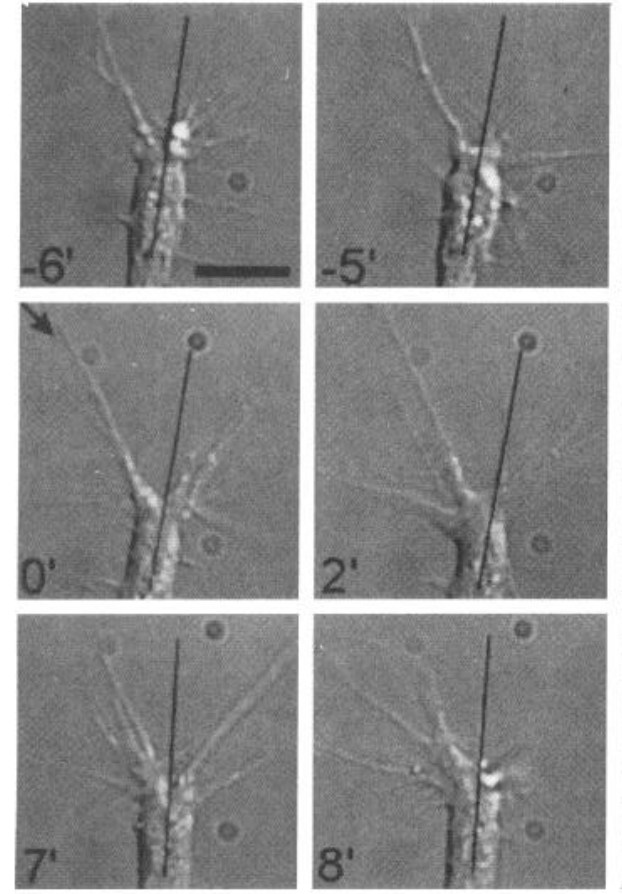
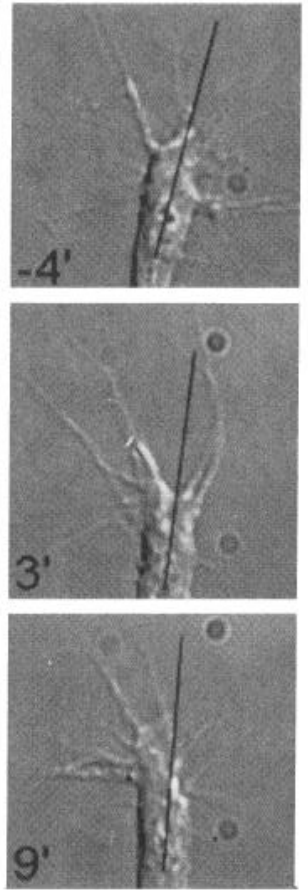
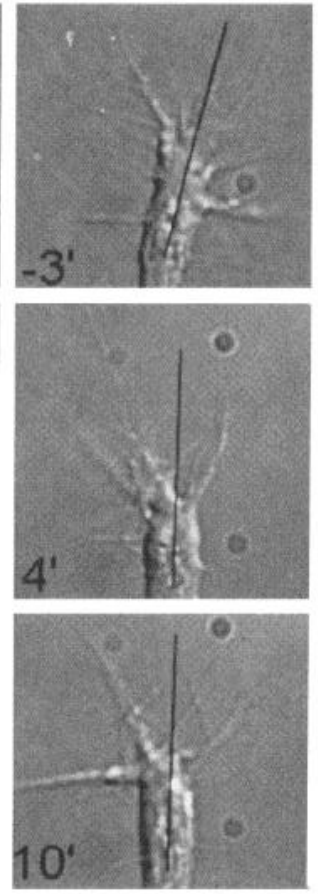
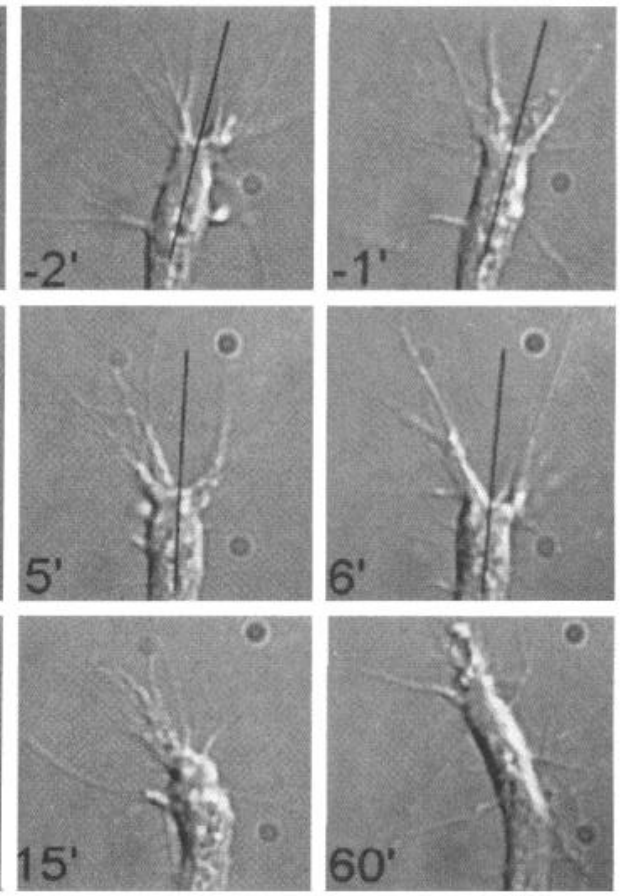

Figure 3. Asymmetric filopodia formation induced by a glutamate gradient. A sequence of DIC images of a growth cone at various times before and after (indicated by numbers in $\mathrm{min}$ ) the onset of a glutamate gradient $(0.5 \mathrm{~mm}$ in the pipette), which was applied at time 0 from the top left corner (arrow). Lines represent the midlines of the last $20 \mu \mathrm{m}$ segment of neurite. Scale bar, $10 \mu \mathrm{m}$.

\section{Asymmetric filopodia formation precedes the turning response}

To understand the dynamic behavior of the growth cone and the role of filopodia during the chemotropic turning, time-lapse DIC microscopy was used to examine the growth cone before and after the onset of the glutamate gradient. In most cases, the turning of the growth cone was preceded by an asymmetry in the distribution of filopodia. Figure 3 illustrates a sequence of DIC images of a growth cone at $1 \mathrm{~min}$ intervals. During the control period ( -6 to $0 \mathrm{~min}$ ), the filopodial activity appeared to be symmetric around a line drawn along the midline of the growth cone shaft. Within minutes after the onset of the glutamate gradient, an increased number of filopodia was observed on the side of the growth cone facing the glutamate source (near), whereas that on the other side 

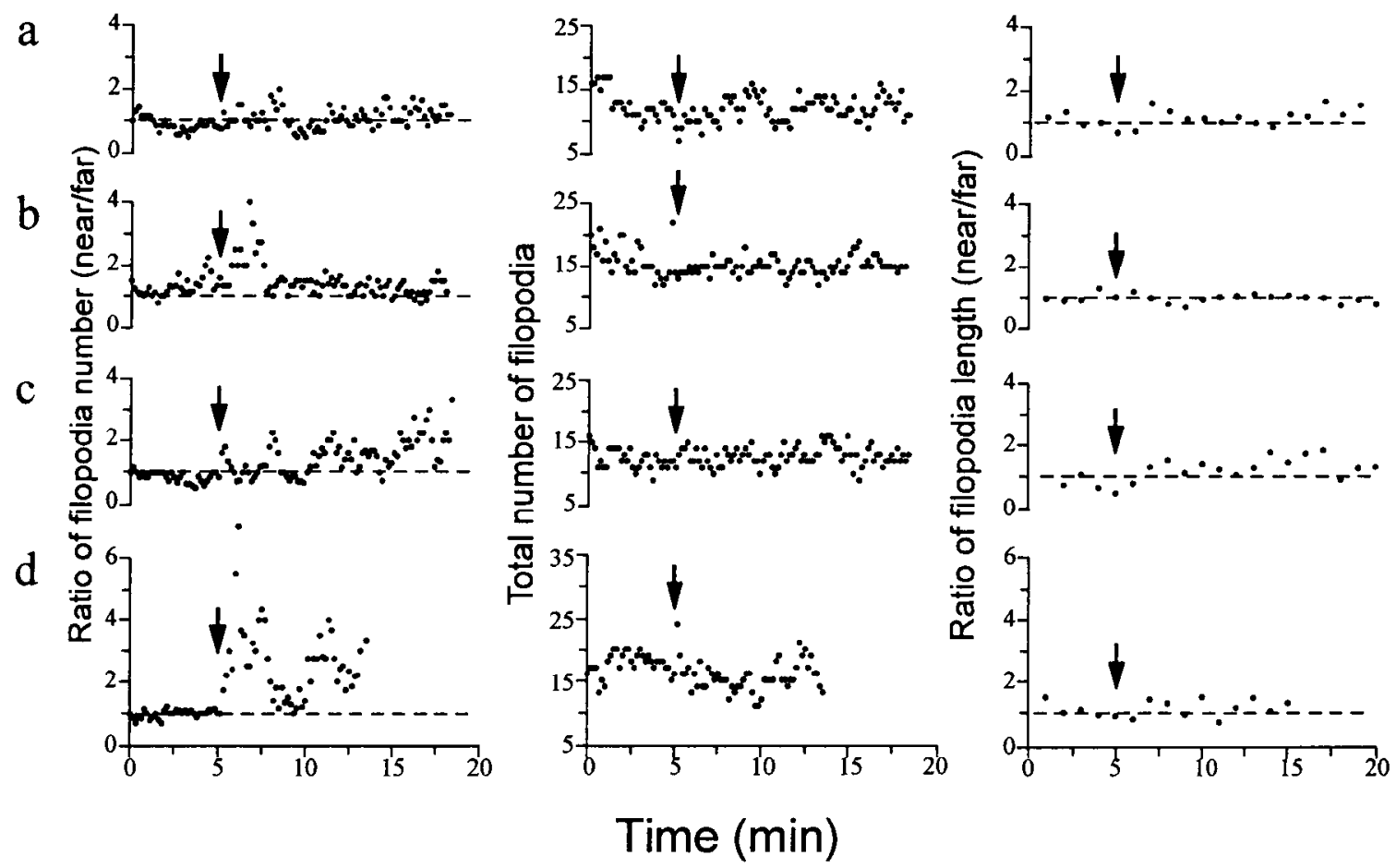

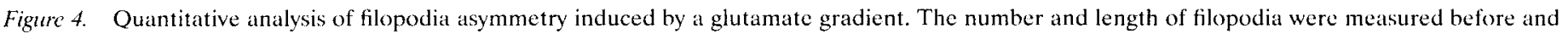

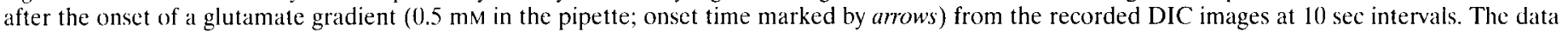

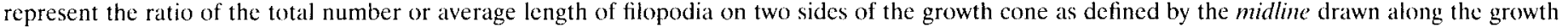

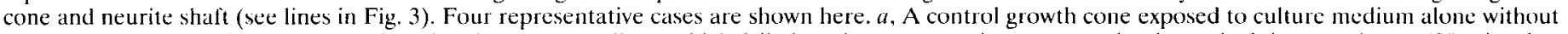

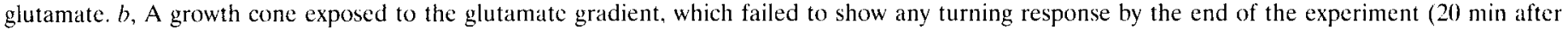

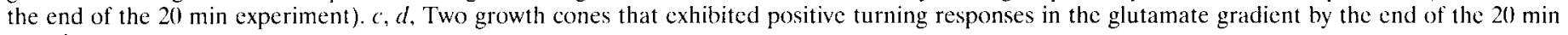
experiment.

of the growth conc (far) was reduced. Such filopodia asymmetry persisted until a clear turning of the growth cone shaft was detected.

To assess the filopodial activity quantitatively, we measured the number and the average length of filopodia on both sides of the growth cone before and after the onset of the glutamate gradient, but before any obvious turning of the growth cone palm. No asymmetry in the filopodia number or length was observed in control experiments when culture medium was applied (Fig. $4 a$ ). Marked asymmetry, as indicated by the ratio of filopodia numbers on the two sides (near vs far) of the growth cone, was observed within minutes after the onset of the glutamate gradient (Fig. $4 b-d$ ), whereas no obvious change in the ratio of average filopodia length on the two sides was observed. Of 13 growth cones examined, 9 showed positive turning at the end of the experiment ( 30 min after the onset of the gradient). All 9 growth cones exhibited persistent asymmetry in filopodia number before actual turning (Kruskal-Wallis test, $p<0.01$ ). For the four growth cones that did not turn, one showed transient asymmetry (Fig. $4 b$ ) and three showed no asymmetry throughout the experiment $(p>0.05)$. This apparent correlation between the asymmetry in filopodia number and the turning response suggests that preferential formation of filopodia is an early event that may be causally related to the turning of the growth cone. It is of interest to note that, whereas the distribution of filopodia number became asymmetric after the onset of the glutamate gradient, the total number of filopodia was unchanged (Fig. 4). Careful examination of the time-lapsed sequence of growth cone behavior showed that the asymmetry was attributable to a redistribution of existing filopodia to the near side of the growth cone, as well as to an asymmetric protrusion/ retraction of filopodia on both sides of the growth cone. The mechanism responsible for maintaining a relatively constant number of filopodia is unknown.

To depict the overall filopodia response to the glutamate gradient better, results from all 13 growth cones examined were averaged and shown in Figure $5 a$. It is clear that filopodia asymmetry appeared within a few minutes after the onset of the glutamate gradient. Similar to the turning response, the filopodia asymmetry induced by the glutamate gradient also requires the presence of extracellular $\mathrm{Ca}^{2+}$. We examined the filopodia dynamics of the growth cones exposed to the glutamate gradicnt in a $\mathrm{Ca}^{2+}$-free medium and performed the same quantitative analysis. As summarized in Figure $5 b$, for 10 growth cones examined, no filopodia asymmetry was observed after the onset of the glutamate gradient at the optimal concentration $(0.5 \mathrm{~mm}$ glutamate in pipette). In all of these cases, no subsequent turning response was observed.

\section{Effect of CB on filopodial activity}

To determine further the role of filopodia in glutamate-induced chemotropic turning of the growth cone, we have examined the turning response after filopodia were eliminated by treatment with $\mathrm{CB}$. CB is a fungal metabolite that is known to disrupt cytoplasmic F-actin (Cooper, 1987), the primary cyloskeletal component of filopodia. We found that $\mathrm{CB}$ at low concentrations $(0.1-0.5 \mu \mathrm{g} / \mathrm{ml})$ could abolish the filopodia effectively, causing only a small reduction in the rate of neurite extension. As shown in Figure 6, $a$ and $b$, filopodia started to disappear soon after the application of $0.17 \mu \mathrm{g} / \mathrm{ml} \mathrm{CB}$ and essentially were eliminated by $20 \mathrm{~min}$. The average filopodia number per growth cone dropped 


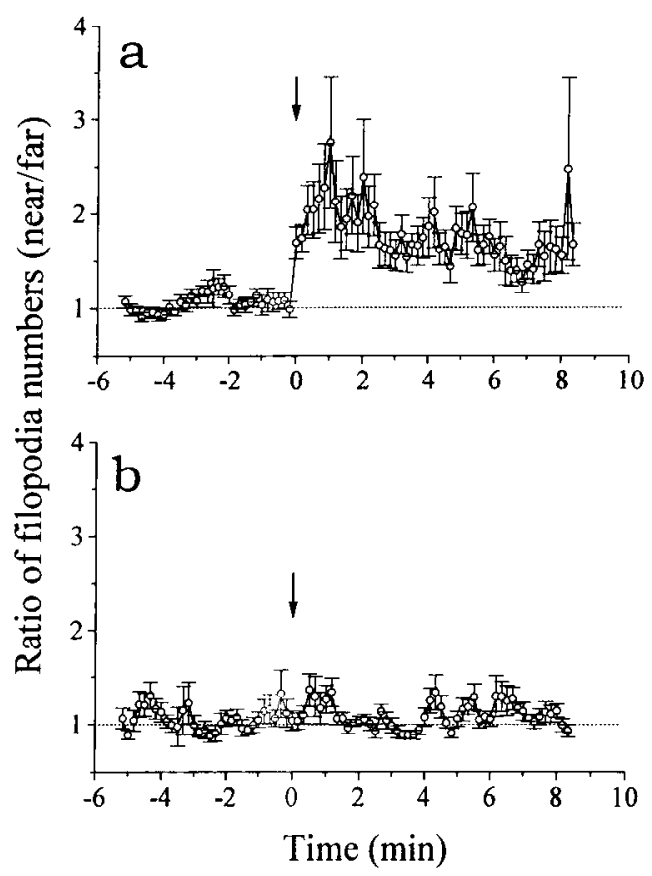

Figure 5. Filopodia asymmetry induced by a glutamate gradient in $(a)$ culture medium $(n=13)$ and $(b) \mathrm{Ca}^{2+}$-free medium $(n=10)$. The data represent the averaged ratio of the filopodia number on the two sides of the growth cone as defined by the midline drawn along the growth cone and neurite shaft (see Fig. 3). The ratio was obtained from the numbers of filopodia that were measured before and after the onset of a glutamate gradient $(0.5 \mathrm{~mm}$ in the pipette; onset time marked by the arrows) from the recorded time-lapse DIC images, which were performed at a rate of 1 frame/10 sec. Filopodia asymmetry was evident for growth cones exposed to the glutamate gradient in culture medium (Kruskal-Wallis test, $p<$ $0.01)$, but not for those in the $\mathrm{Ca}^{2+}$-free medium $(p>0.05)$.

from $6.6 \perp 0.4$ to $0.3 \perp 0.1(n-17)$ after $20 \mathrm{~min}$ of $0.17 \mu \mathrm{g} / \mathrm{ml} \mathrm{CB}$ treatment. Occasionally, a single, immobile filopodium was found to remain after the $20 \mathrm{~min} C B$ treatment, perhaps because of its strong adhesion to the substrate. Time-lapse DIC recording also revealed that the reduction in filopodia number is accompanied by a reduced motility of the filopodia. Immediately after CB was added to the medium, active protrusions and retractions of filopodia ceased and filopodia began to withdraw.

By staining the neuron with rhodamine-conjugated phalloidin, we have examined the distribution of F-actin in growth cones with and without $\mathrm{CB}$ treatment. At the low concentration of $\mathrm{CB}(0.17$ $\mu \mathrm{g} / \mathrm{ml}$ ), filopodia were eliminated within $20 \mathrm{~min}$, but the distribution of F-actin within the growth cone and the neurite shaft (Fig. $6 d)$ was similar to that observed in the growth cone not treated with CB (Fig. 6c). In particular, the cortical actin staining beneath the plasmalemma appeared to remain intact after this $C B$ treatment. In contrast, treatment of the growth cone with a higher concentration of $\mathrm{CB}(5 \mu \mathrm{g} / \mathrm{ml})$ drastically altered the F-actin distribution (Fig. 6e), causing a punctate phalloidin staining. At this high concentration of $\mathrm{CB}$, which is known to cause a complete disruption of the F-actin network (MacLean-Fletcher and Pollard, 1980; Forscher and Smith, 1988), neurite extension was essentially inhibited.

\section{Effect of CB on chemotropic turning}

Glutamate-induced turning of growth cones was examined in the presence of $0.17 \mu \mathrm{g} / \mathrm{ml} \mathrm{CB}$ in the culture medium. The glutamate gradient was applied near the growth cone $20 \mathrm{~min}$ after the addition of CB. After $1 \mathrm{hr}$ in the presence of the glutamate gradient $(0.5 \mathrm{~mm}$ glutamate in pipette), no preferential turning toward the glutamate source was observed. The average turning response of $\mathrm{CB}$-treated neurons was not significantly different from that of the control (no glutamate), although the average length of neurite extension was reduced (see Table 1). An example of the lack of chemotropic response of CB-treated neurons is shown in Figure $7 a-c$. The results of all experiments $(n=27)$ are summarized in Table 1.

It is unlikely that the abolition of glutamate-induced turning by CB treatment is attributable to the loss of the growth cone's ability to turn. As shown by the trajectory of neurite extension in the absence of glutamate gradient during a $2 \mathrm{hr}$ period (Fig. $7 d, e^{e}$ ), CB-treated growth cones (Fig. 7e) still turn in a haphazard manner similar to those without $\mathrm{CB}$ treatment (Fig. $7 d$ ), although a reduction in both the extension and the directional deviation from the original direction of extension (vertical axis) was observed. Thus, active filopodial activity may contribute primarily to the directed growth induced by extracellular cues.

\section{DISCUSSION}

\section{Glutamate effects on nerve growth and turning}

Extracellular application of serotonin, dopamine, or glutamate causes an inhibition of growth cone motility and neurite extension in a number of culture systems (Haydon et al., 1984; Lankford et al., 1988; Mattson et al., 1988; McCobb et al., 1988), apparently via an excessive elevation of cytosolic $\mathrm{Ca}^{2+}\left(\left[\mathrm{Ca}^{2+}\right]_{i}\right)$ at the growth cone (Mattson and Kater, 1988; McCobb et al., 1988) (for review, see Kater and Mills, 1991). However, glutamate also induces rapid filopodia protrusion from hippocampal neurites (Smith and Jahr, 1992) and from culturcd astrocytes (Corncll-Bcll ct al., 1992). In the present study, we observed positive turning responses of growth cones of Xenopus spinal neurons in an extracellular gradient of glutamate, similar to that found for ACh (Zheng et al., 1994). In both cases, the presence of extracellular $\mathrm{Ca}^{2+}$ is required for the turning response, suggesting that $\mathrm{Ca}^{2+}$ influx through transmitter channels is responsible for inducing the turning response. A gradient of $\left[\mathrm{Ca}^{2+}\right]_{i}$ was observed in the growth cone soon after the onset of the $\mathrm{ACh}$ gradient (Zheng et al., 1994).

The concentration of glutamate reaching the growth cone is estimated to be $\sim 10^{3}$-fold lower than that in the pipette (Lohof et al., 1992; Zheng et al., 1994). Thus, the average glutamate concentrations at the growth cone for effective chemotropic action would be $\sim 0.05$ and $0.5 \mu \mathrm{M}$, which is two to three orders of magnitude lower than the ACh concentration required for inducing a chemotropic turning (Zheng et al., 1994). This difference may be attributed to differences in the receptor density, $\mathrm{Ca}^{2+}$ permeability, or ligand-binding affinity for these two types of receptors in Xenopus neurons. The finding that the chemotropic response was observed only for a narrow range of glutamate concentrations (i.e., 0.05 and $0.5 \mathrm{~mm}$ ) is consistent with the hypothesis that an optimal level and/or a gradient of $\left[\mathrm{Ca}^{2+}\right]_{i}$ are required for the turning response. At low glutamate concentrations, an insufficient number of glutamate receptors may have been activated on either side of the growth cone to induce sufficient $\mathrm{Ca}^{2+}$ influx. At high glutamate concentrations, all receptors on the growth cone may have been activated, causing a uniform elevation of $\left[\mathrm{Ca}^{2+}\right]_{i}$ across the growth cone. 

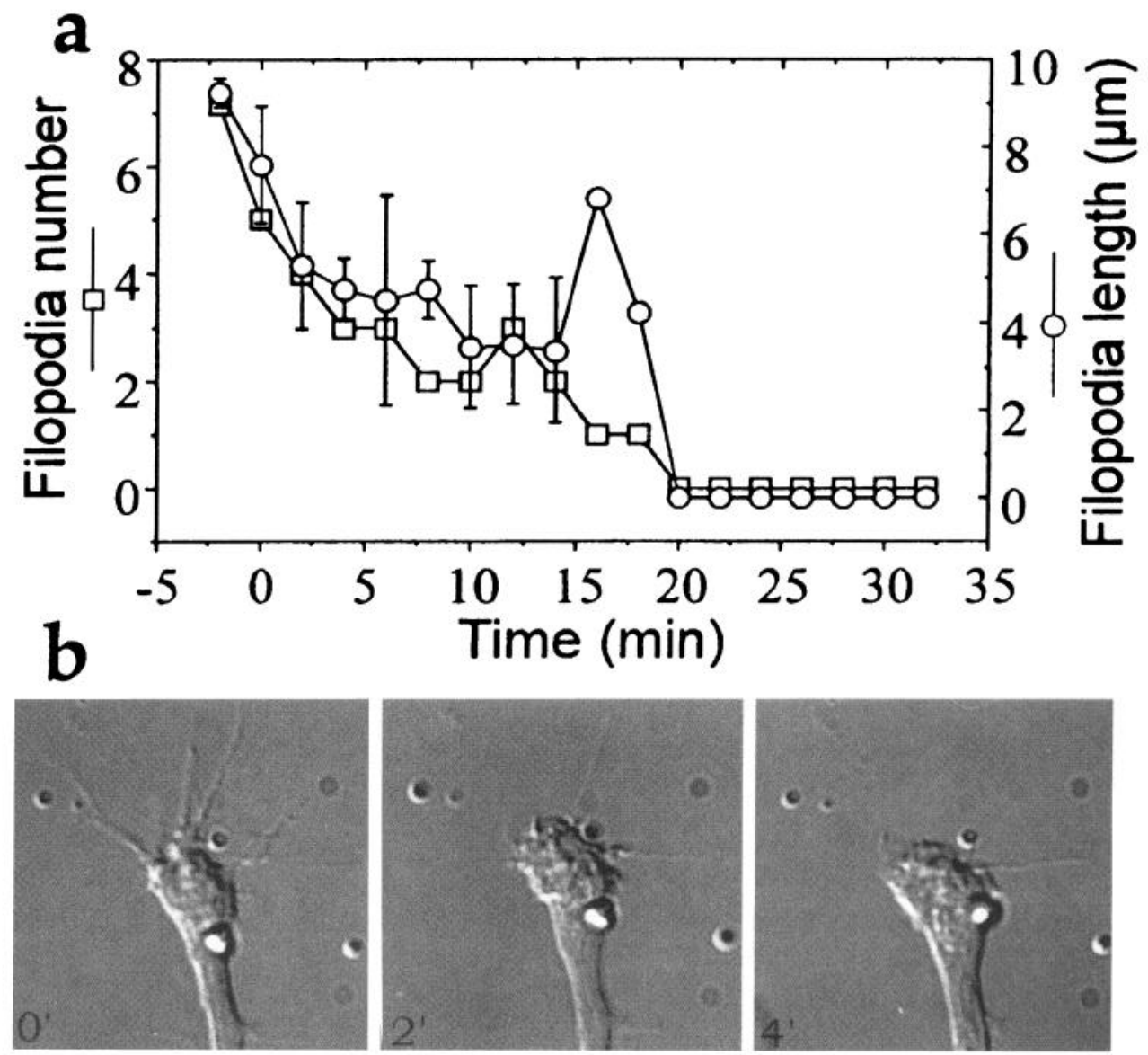

Figure 6. Effects of $\mathrm{CB}$ on growth cone filopodia. $a$, The decline of the filopodia number and filopodia length of a growth cone after $\mathrm{CB}$ treatment $(0.17 \mu \mathrm{g} / \mathrm{ml})$ over time for a typical growth cone. $b$, A sequence of DIC images recorded at different times (numbered in min) after the growth cone was exposed to $\mathrm{CB}$ at a concentration of $0.17 \mu \mathrm{g} / \mathrm{ml}$. Scale bar, $10 \mu \mathrm{m}$. $c-e$, The distribution of $\mathrm{F}$-actin in growth cones without $(c)$ and with $(d, e) \mathrm{CB}$ treatment as revealed by rhodamine-phalloidin staining. $d$, The growth cone was exposed to 0.17 $\mu \mathrm{g} / \mathrm{ml} \mathrm{CB}$ for $20 \mathrm{~min}$ before staining. Note that cortical actin staining appears similar to that in the control growth cone shown in $c$. $e$, The growth cone was exposed to $5 \mu \mathrm{g} / \mathrm{ml}$ CB for $20 \mathrm{~min}$. Scale bar, $10 \mu \mathrm{m}$.
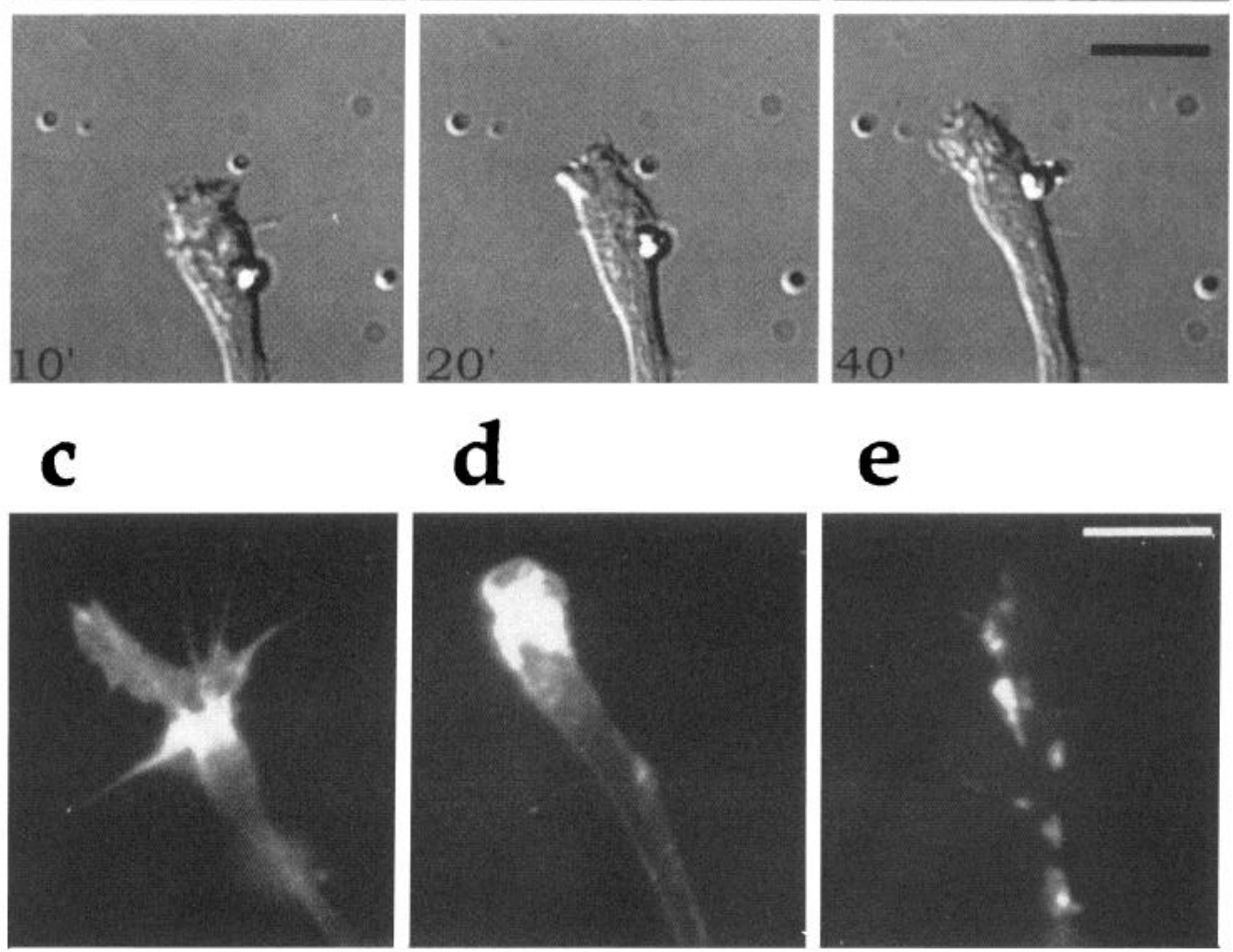
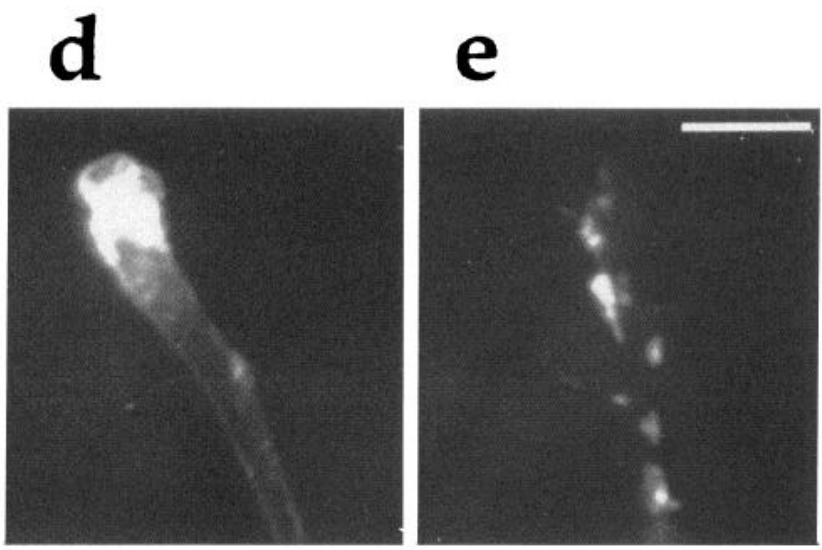

\section{Involvement of glutamate receptors}

Glutamate receptors were found in developing Xenopus spinal neurons (Nicoll et al., 1976; Bixby and Spitzer, 1984b; Dale and Roberts, 1985). NMDA receptors, a subtype of glutamate receptors with a high permeability to $\mathrm{Ca}^{2+}$, are expressed in immature cerebellar granule neurons (Burgoyne et al., 1988; Howe et al., 1991) and developing spinal neurons (Kalb et al., 1992) before synaptogenesis. There is also evidence that NMDA receptors are involved in neuronal migration in the cerebellum (Komuro and Rakic, 1993). Glutamate-induced chemotropic turning of Xenopus 

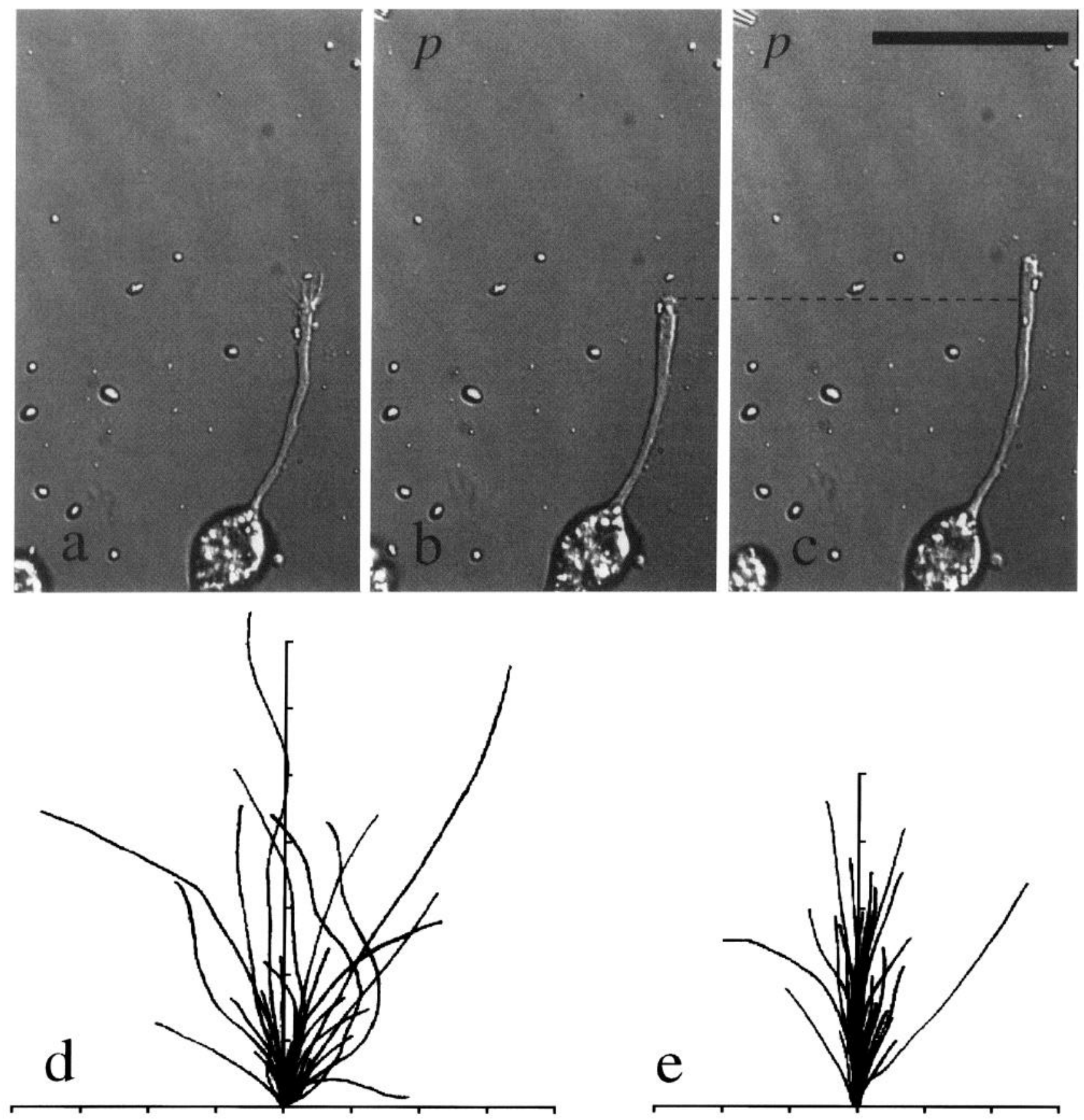

Figure 7. Effect of $\mathrm{CB}$ on glutamate-induced chemotropic turning of Xenopus growth cones. $a$, A spinal neuron before exposure to CB and glutamate. $b$, Twenty minutes after the addition of $0.17 \mu \mathrm{g} / \mathrm{ml} \mathrm{CB}$ in bath, the glutamate gradient was established by the pulsatile ejection of solution containing 0.5 mM glutamate from the tip of a micropipette $(p) . c$, Sixty minutes after the onset of the glutamate gradient, the growth cone extended without turning. Scale bar, $50 \mu \mathrm{m} . d, e$, The behavior of growth cones in the absence $(d)$ and presence $(e)$ of $0.17 \mu \mathrm{g} / \mathrm{ml} \mathrm{CB}$ was illustrated as composite tracings of the trajectory of the net neurite extension over a $2 \mathrm{hr}$ period without the glutamate application (for tracing method, see Fig. 2 legend). Tick marks along the $x$ - and $y$-axis represent $10 \mu \mathrm{m}$.

spinal neurons appears to involve NMDA receptors directly because the turning response was blocked by AP-5 (see Table 1). Asymmetric activation of NMDA receptors on the two sides of the growth cone by the glutamate gradient could cause an asymmetric $\mathrm{Ca}^{2+}$ influx at the growth cone which, in turn, could induce the turning response. However, with $\mathrm{Mg}^{2+}$ present in the culture medium $(\sim 1 \mathrm{~mm})$, the turning response also required the activation of non-NMDA glutamate receptors, because it could be abolished by CNQX. It is likely that the $\mathrm{Mg}^{2+}$ block of NMDA receptors was removed by the membrane depolarization (Nowak et al., 1984; Jahr and Stevens, 1987) caused by the activation of non-NMDA receptors. Thus, the activation of both types of glutamate receptors is required for the turning response in normal culture medium. Indeed, we found that activation of non-NMDA receptors was no longer required in the absence of extracellular $\mathrm{Mg}^{2+}$ (Table 1), whereas activation of NMDA receptors was still necessary. These findings also suggest that the contribution of $\mathrm{Ca}^{2+}$ influx through voltage-dependent $\mathrm{Ca}^{2+}$ channels caused by 
depolarization induced by non-NMDA receptors was insignificant for the turning response.

\section{Filopodia asymmetry before growth cone turning}

$\mathrm{Ca}^{2+}$ is known to influence cytoskeletal dynamics and organization. A large influx of $\mathrm{Ca}^{2+}$ through membrane transmitter channels or voltage-dependent $\mathrm{Ca}^{2+}$ channels has been shown to induce inhibition or retraction of growth cones (Cohan et al., 1987; Mattson and Kater, 1988; McCobb et al., 1988), whereas a gradient of $\mathrm{Ca}^{2+}$ influx appears to induce a chemotropic turning response (Zheng et al., 1994). Filopodia contain an actin core, the dynamics of which, therefore, could be affected by an elevation in $\left[\mathrm{Ca}^{2+}\right]_{\mathrm{i}}$ directly or by $\mathrm{Ca}^{2+}$-dependent actin-binding proteins (Mitchison and Kirschner, 1988; Forscher, 1989; Bamburg and Bernstein, 1991). A local increase in $\left[\mathrm{Ca}^{2+}\right]_{i}$ was found to elicit local filopodia protrusion (Davenport and Kater, 1992). We found that when extracellular $\mathrm{Ca}^{2+}$ was depleted filopodia asymmetry was not induced by the glutamate gradient, and no subsequent growth cone turning was induced. Therefore, the preferential filopodia formation may be mediatcd by asymmctric $\mathrm{Ca}^{2+}$ influx in the presence of a glutamate gradient. The close correlation hetween the appearance of persistent asymmetry and eventual growth cone turning suggests further that an asymmetry in filopodia is an early cellular event that determines the direction of neurite extension. Our results provide quantitative analyses that substantiate previous observations of filopodia asymmetry before the growth cone turning response (Gundersen and Barrett, 1980; McCaig, 1986; Zheng et al., 1994).

\section{Effects of CB treatment}

The essential role of filopodia in contact-mediated growth cone guidance in vivo has been demonstrated clearly by using cytochalasins (Bentley and Toroian-Raymond, 1986; Chien et al., 1993). We have used a similar approach to examine whether the presence of filopodia also are required for chemotropic guidance of the growth cone by glutamate. We found that elimination of filopodia by the low concentration $(0.17 \mu \mathrm{g} / \mathrm{ml})$ of CB completely blocked the turning response, whereas the neurite extension was reduced only slightly. Fluorescence staining with rhodaminephalloidin showed that CB at this low concentration effectively removes filopodia without substantially affecting the F-actin distribution in the growth cone palm and neurite shaft. This effect of $\mathrm{CB}$ is unlikely to be attributable to the side effect on hexose transport (Lin and Spudich, 1974). Cytochalasin D, which is more specific in disrupting F-actin (Goddette and Frieden, 1986), also eliminated filopodia and abolished glutamate-induced turning ( $\mathrm{J}$. Zheng, unpublished observations).

Filopodia activity depends on the actin dynamics in the growth cone. An asymmetric filopodia distribution observed during the turning response is likely caused by an asymmetry in actin polymerization. $\mathrm{CB}$ affects the actin dynamics by binding to the barbed end of actin filaments, which prevents further polymerization and leads to the depolymerization of actin filaments. Actin filaments undergo rapid polymerization and depolymerization in motile filopodia and, therefore, are most susceptible to the disruption by CB. However, we cannot rule out that, in addition to its effect on filopodia, the low concentration of CB used also affected other functions of actin filaments in the growth cone that are responsible for the turning response. Our result that CB-treated growth cones in the absence of extracellular cues still exhibited turning in a haphazard manner similar to that of untreated growth cones suggests that the growth cone remained capable of spontaneous turning after the $\mathrm{CB}$ treatment.

\section{Potential functions of filopodia}

Removal of filopodia by $\mathrm{CB}$ may lead to two immediate consequences on the chemotropic response of the growth cone. Assuming that glutamate receptors are distributed along the membrane of entire filopodia (average length $7 \mu \mathrm{m}$ ), the spatial gradient sampled by the growth cone will be reduced by at least twofold after the elimination of filopodia (Lohof et al., 1992; Zheng et al., 1994). The resulting asymmetry of $\mathrm{Ca}^{2+}$ influx on two sides of the growth cone likely would be reduced similarly. The absence of filopodia also eliminates the structural element responsible for generating an asymmetric tension that may help to orient the direction of neurite extension (Heidemann et al., 1990). However, it is known that neurite extension does not require the presence of filopodia and that cellular processes involved in nerve growth, e.g., microtubule polymerization and/or insertion of new plasma membrane, can proceed in the absence of the tension generated by filopodia (Marsh and Letourneau, 1984; Letourneau et al., 1987). Filopodia-free growth cones also were found to exhibit preferential turning under the influence of an electric field (McCaig, 1989). Although these previous findings suggest that the tension produced by filopodia is not necessary for either the extension or the turning of the growth cone, we cannot exclude the possibility that, in the case of chemotropic turning responses, rapid induction of asymmetric filopodial activity leads to an asymmetric tension that facilitates the turning response.

In conclusion, we have shown that filopodia play an important role in glutamate-induced chemotropic turning of nerve growth cones. Our results suggest that asymmetric $\mathrm{Ca}^{2+}$ influx at the growth cone, filopodia asymmetry, and the turning of the growth cone comprise a sequence of causally related events. Inhibition of filopodia asymmetry by depleting extracellular $\mathrm{Ca}^{2}$ or eliminating filopodia by a low concentration of cytochalasins abolished the chemotropic turning. Although as yet there is no evidence that glutamate plays a role in axonal guidance in vivo, the present study provides useful information concerning cellular mechanisms used by the growth cone to detect and respond to diffusible extracellular guidance cues.

\section{REFERENCES}

Bamburg JR, Bernstein BW (1991) Actin and actin-binding proteins in neurons. In: The neuronal cytoskeleton (Burgoyne RD, ed). pp 121160. New York: Wilcy.

Bandtlow C, Zachleder T, Schwab WE (1990) Oligodendrocytes arrest neurite growth by contact inhibition. J Neurosci 10:3837-3848.

Bentley D, Toroian-Raymond A (1986) Disoriented pathfinding by pioneer neurone growth cones deprived of filopodia by cytochalasin treatment. Nature 323:712-715.

Bixby JL, Spitzer NC (1984a) Early differentiation of vertebrate spinal neurons in the absence of voltage-dependent $\mathrm{Ca}^{2+}$ and $\mathrm{Na}^{+}$influx. Dev Biol 106:89-96.

Bixby JL, Spitzer NC (1984b) The appearance and development of neurotransmitter sensitivity in Xenopus embryonic spinal neurones in vitro. J Physiol (Lond) 353:143-155.

Bray D, Hollenbeck PJ (1988) Growth cone motility and guidance. Annu Rev Cell Biol 4:43-61.

Burgoyne RD, Pearce IA, Cambray-Deakin M (1988) N-methyl-I)aspartate raises cytosolic calcium concentration in rat cercbellar granule cells in culture. Neurosci Lett 91:47-52.

Chien C-B, Rosenthal DE, Harris WA, Holt CE (199.3) Navigational errors made by growth cones without filopodia in the embryonic Xenopus brain. Neuron 11:237-251

Cohan CS, Connor JA, Kater SB (1987) Electrically and chemically mediated increases in intracellular calcium in neuronal growth cone. $J$ Neurosci 7:3588-3599.

Cooper JA (1987) Effects of cytochalasin and phalloidin on actin. J Cell Biol 105:1473-1478. 
Corncll-Bell AII, Thomas PG, Caffrey JM (1992) $\mathrm{Ca}^{2+}$ and filopodia responses to glutamate in cultured astrocytes and neurons. Can $\mathbf{J}$ Physiol Pharmacol [Suppl] 70:S206-S218.

Dale N, Roberts A (1985) Dual-component amino-acid-mediated synaptic potentials: excitatory drive for swimming in Xenopus embryos. J Physiol (Lond) 363:35-39.

Davenport RW, Kater SB (1992) Local increases in intracellular calcium elicit local filopodial responses in Helisoma neuronal growth cones. Neuron 9:405-416.

Davenport RW, Dou P, Rehder V, Kater SB (1993) A sensory role for neuronal growth cone filopodia. Nature 361:721-724.

Forscher P (1989) Calcium and polyphosphoinositide control of cytoskeletal dynamics. Trends Neurosei 12:468-474.

Forscher P, Smith SJ (1988) Actions of cytochalasins on the organization of actin filaments and microtubules in a neuronal growth cone. J Cell Biol 107:1505-1516.

Goddette DW, Frieden C (1986) Actin polymerization: the mechanism of action of cytochalasin D. J Biol Chem 261:15974-15980.

Gomez TM, Letourneau PC (1994) Filopodia initiate choices made by sensory neuron growth cones at laminin/fibronectin borders in vitro. J Neurosci 14:5959-5972.

Goodman CS, Shatz CJ (1993) Developmental mechanisms that generate precise patterns of neuronal connectivity. Neuron [Suppl] 10:77-98.

Gundersen RW, Barrett JN (1980) Characterization of the turning response of dorsal root neurites towards nerve growth factor. J Cell Biol $87: 546-554$.

Haydon PG, McCobb DP, Kater SB (1984) Serotonin selectively inhibits growth cone motility and synaptogenesis of specific identified neurons. Science 226:561-564.

Heidemann SR, Buxbaum RE (1991) Growth cone motility. Curr Opin Neurobiol 1:339-345.

Heidemann SR, Lamoureux P, Buxbaum RE (1990) Growth cone behavior and production of traction force. J Cell Biol 111:1949-1957.

Howe JR, Cull-Candy SG, Colquhoun D (1991) Currents through single glutamate receptor channels in outside-out patches from rat cerebellar granule cells. J Physiol (Lond) 432:143-202.

Jahr CE. Stevens CF (1987) Glutamate activates multiple single channel conductances in hippocampal neurons. Nature 325:522-525.

Kalb RG, Lidow MS, Halsted MJ, Hockfield S (1992) N-methyl-Daspartate receptors are transiently expressed in the developing spinal cord ventral horn. Proc Natl Acad Sci USA 89:8502-8506.

Kater SB, Mills LR (1991) Regulation of growth cone behavior by calcium. J Neurosci 11:891-899.

Komuro H, Rakic P (1993) Modulation of neuronal migration by NMDA receptors. Science 260:95-97.

Lamoureux P, Buxbaum KE, Heidemann SR (1989) Direct evidence that growth cones pull. Nature 340:159-162.

Lankford KL. DeMello FG, Klein WL (1988) $D_{1}$-type dopamine receptors inhibit growth cone motility in cultured retina neurons: evidence that neurotransmitters act as morphogenic growth regulators in the developing central nervous system. Proc Natl Acad Sci USA $86: 2839-2843$.

Letourneau PC (1992) Growth cone motility. Curr Opin Cell Motil $4: 4-7$.

Letourneau PC, Kater SB, Macagno E (1991) The nerve growth cone. New York: Raven.

Letourneau PC, Shattuck TA, Ressler AH (1987) "Pull" and "push" in neurite elongation: observations on the effects of different concentrations of cytochalasin B and taxol. Cell Motil Cytoskeleton 8:193-209.
Lin S, Spudich JA (1974) Biochemical studies on the mode of action of cytochalasin $B$ binding to red blood cell membrane in relation to glucose transport. J Biol Chem 249:5778-5783.

Lockerbie RO (1987) The neuronal growth cone: a review of its locomotory navigational and target recognition capabilities. Neuroscience 20:719-729.

Lohof AM, Quillan M, Dan Y, Poo M-m (1992) Asymmetric modulation of cytosolic cAMP activity induces growth cone turning. J Neurosci $12: 1253-1261$.

MacLean-Fletcher S, Pollard TD (1980) Mechanism of action of cytochalasin $\mathrm{B}$ on actin. Cell 20:329-341.

Marsh L, Letourneau PC (1984) Growth of neurites without filopodial or lamellipodial activity in the presence of cytochalasin B. J Cell Biol 99:2041-2047.

Mattson MP, Kater SB (1988) Excitatory and inhibitory ncurotransmitters in the generation and degeneration of hippocampal neuroarchitecture. Brain Res 478:337-348.

Mattson MP, Dou P, Kater SB (1988) Outgrowth regulating actions of glutamate in isolated hippocampal pyramidal neurons. J Neurosci $8: 2087-2100$.

McCaig CD (1986) Dynamic aspects of amphibian neurite growth and the effects of an applied electric field. J Physiol (Lond) 375:55-69.

McCaig CD (1989) Nerve growth in the absence of growth cone filopodia and the effects of a small applied electric field. J Cell Sci 93:715-721.

McCobb DP, Haydon PG, Kater SB (1988) Dopamine and serotonin inhibition of neurite outgrowth of different identified neurons. J Neurosci Res 19:19-26.

Nicoll RA, Padjen A, Barker JL (1976) Analysis of amino acid responses on frog motoneurones. Neuropharmacology 15:45-53.

Nieuwkoop PD, Faber J (1967) Normal table of Xenopus lacvis, 2nd Ed. Amsterdam: Elsevier.

Nowak L, Bregestovski P, Ascher P, Herbet A, Prochiantz A (1984) Magnesium gates glutamate-activated channels in mouse central neurones. Nature $307: 462-465$.

O'Connor TP, Duerr JS, Bentley D (1990) Pioneer growth cone steering decisions mediated by single filopodial contacts in situ. J Neurosci 10:3935-3946.

Raper JA, Bastiani M, Goodman CS (1983) Pathfinding by neuronal growth cones in grasshopper embryos. I. Divergent choices made by the growth cones of sibling neurons. J Neurosci 3:20-30.

Schwartz JP (1992) Neurotransmitters as neurotrophic factors: a new set of functions. Int Rev Neurobiol 34:1-23.

Smith SJ, Jahr CE (1992) Rapid induction of filopodial sprouting by application of glutamate to hippocampal neurons. In: The nerve growth cone (Letourneau PC, Kater SB, Macagno ER, eds), pp 19-26. New York: Raven.

Spitzer NC, Lamborghini JC (1976) The development of the action potential mechanism of amphibian neurons isolated in culture. Proc Natl Acad Sci USA 73:1461-1465.

Tessier-Lavigne M (1992) Axon guidance by molecular gradients. Curr Opin Neurobiol 2:60-65.

Tibti N, Poo M-m (1990) Culturing spina! cord neurons and muscle cells from Xenopus embryos. In: Culture nerve cells (Banker G, Goslin K, eds), pp 137-154. Cambridge: MIT.

Wessells NK, Nuttall RP (1978) Normal branching induced branching and steering of cultured parasympathetic motor ncurons. Exp Cell Res 115:111-122.

Zheng JQ, Felder M, Connor JA, Poo M-m (1994) Turning of nerve growth cones induced by neurotransmitters. Nature 368:140-144. 